\title{
Regional myocardial blood flow in patients with chest pain syndromes and normal coronary arteriograms ${ }^{1,2}$
}

\author{
LAURENCE H. GREEN, PETER F. COHN, B. LEONARD HOLMAN, \\ DOUGLASS F. ADAMS, AND JOHN E. MARKIS
}

From the Departments of Medicine and Radiology, Peter Bent Brigham Hospital and Harvard Medical School, Boston, Mass. 02115, USA

SUMMARY To evaluate possible disorders of regional myocardial blood flow in patients with chest pain syndromes and normal coronary arteriograms, we studied 21 patients with intracoronary injections of Xenon-133. Thirteen patients were restudied during an intervention: 6 patients received glyceryl trinitrate and 7 patients had contrast agent-induced hyperaemia. Patients were divided into 3 clinical groups: 7 patients had classic angina, 7 patients had a mixture of typical and atypical chest pain, and 7 patients had entirely atypical pain. A wide range of normal values for regional myocardial blood flow at rest was noted (41 to $128 \mathrm{ml} / \mathrm{min}$ per $100 \mathrm{~g}$, with an average regional myocardial blood flow of 77 $\mathrm{ml} / \mathrm{min}$ per $100 \mathrm{~g} \pm 7$ (mean \pm SEM)). There were no significant differences between the 3 groups. With contrast hyperaemia, regional myocardial blood flow increased 164 per cent, while with glyceryl trinitrate, it decreased 31 per cent. Again, there was no statistical difference among the groups. Regional abnormalities of flow ( $>15 \%$ difference between distal quadrants) were noted in 3 of 34 measurements. Two patients had heterogeneity of flow at rest by quadrant analysis but no focal perfusion abnormalities detected by functional imaging. Interestingly, both patients had positive exercise tests. Another patient had regional differences only during contrast-induced hyperaemia. Our findings suggest that most patients with chest pain syndromes and normal coronary arteriograms-even those with classic angina-do not have significant measurable myocardial perfusion abnormalities.

The pathophysiology of angina pectoris is usually related to myocardial ischaemia secondary to significant luminal obstruction of the proximal coronary arteries (Zoll et al., 1951). Occasionally, however, patients will present with the typical or quasi-typical symptoms of angina, yet have entirely normal coronary arteriograms and no other recognised cause of myocardial ischaemia (valvular heart disease, hypertension, arteritides, etc.). Some patients with typical (and even atypical) angina may also have evidence of abnormal myocardial function compatible with ischaemia-such as myocardial lactate production with stress (Arbogast and Bourassa, 1972; Boudoulas et al., 1974) and electrocardiographic ST segment depression on exercise testing (Dwyer et al., 1969; Kemp et al., 1973)—others show abnormal left ventricular performance-such as a rise in left

'Supported by USPHS Grants.

${ }^{2}$ Presented in November 1976 at the 49th Annual Session of the American Heart Association, Miami Beach, Florida, USA.

Received for publication 29 July 1977 ventricular end-diastolic pressure (LVEDP) with exercise (Bemiller et al., 1973) and atrial pacing (Mammohansingh and Parker, 1975) or by 'supranormal' ejection fractions at rest (Sample et al., 1974).

If abnormalities in the delivery of blood to the myocardium are responsible for chest pain in this syndrome, there should be derangements in regional or whole heart blood flow. This aspect of the syndrome has not been extensively studied because of lack of appropriate techniques for determining regional myocardial blood flow in humans. In a preliminary report, Dwyer and colleagues (1972), using the xenon-133 washout technique, noted normal blood flow at rest in a small number of patients with this syndrome. We have investigated this further by measuring myocardial blood flow with the xenon-133 washout technique (at rest and with several interventions designed to alter flow) in a larger number of patients with chest pain and normal coronary arteriograms. As in a previous study from this hospital (Kemp et al., 1973), we have grouped our patients according to the charac- 
teristics of their angina since patients with the more classic anginal histories often provide the most challenging clinical problems.

\section{Subjects and methods}

The study population consisted of 21 patients with chest pain syndromes who underwent coronary angiography between April 1972 and February 1976 to determine whether obstructive coronary artery disease was present. There were 15 men and 6 women ranging in age from 34 to 57 years (mean 46 years). At cardiac catheterisation, no patients had evidence of valvular or congenital heart disease or an overt cardiomyopathy (as defined by both an ejection fraction less than 0.50 and a resting LVEDP greater than $15 \mathrm{mmHg}$ ).

\section{CLINICAL DATA}

Histories and physical examinations were confirmed by at least two physicians from the Cardiovascular Division. A detailed description of the pain, its precipitating factors, relief by glyceryl trinitrate, and the presence of risk factors associated with coronary atherosclerosis were included in the history. For purposes of this study, risk factors were defined as follows: cigarette smoking -at least half a packet a day within the past 5 years; hypertension $=$ blood pressure of $140 / 90 \mathrm{mmHg}$ on more than one occasion; hypercholesterolaemia $=$ serum cholesterol $>250 \mathrm{mg} / 100 \mathrm{ml}$; diabetes mellitus = fasting or 2-hour postprandial blood sugar $>120 \mathrm{mg} / 100 \mathrm{ml}$. In addition to a standard 12 lead electrocardiogram at rest, all patients underwent submaximal exercise stress testing, initially by a two-step double Master's procedure and later in the study by bicycle ergometer or a graded treadmill exercise tolerance test. Each test was continued until the patient had completed the procedure or was limited by severe chest pain or fatigue and/or dyspnoea. Flat or downsloping depression of the ST segment of at least $1.0 \mathrm{~mm}$ was required for a positive test (Bruce and Hornstein 1969). The test was scored as indeterminant if neither ischaemic ST segment depression nor the target heart rate was achieved $(85 \%$ of maximum for the bicycle ergometer and treadmill (Bruce and Hornstein, 1969), and a rate of 110 beats/min for the two-step (Cohn et al., 1972)).

\section{CATHETERISATION DATA}

Standard right and left heart catheterisation, selective coronary angiography, and left ventriculography were performed on each patient in the fasting state with diazepam premedication. Right and left heart haemodynamic measurements were obtained using fluid-filled catheters with Statham P23DB strain, gauges. Coronary arteriography was performed with Renografin radiographic contrast material, using the femoral technique. No attempt was made to induce coronary spasm with pharmacological agents. The coronary arteriograms were recorded on 16 or $35 \mathrm{~mm}$ cine film via multiple selective injections of both coronary arteries in several projections. Left ventriculography was performed either in the right anterior oblique (RAO) projection alone or by biplane cine (RAO plus left anterior oblique (LAO) projection). All films were reviewed independently by at least two members of the staff, with uniform agreement on ventriculographic findings as well as the absence of coronary arterial lesions other than minor luminal irregularities.

\section{REGIONAL MYOCARDIAL SPECIFIC BLOOD}

FLOW MEASUREMENTS

At the conclusion of the catheterisation and at least 20 minutes after the last diagnostic coronary injection, measurements of regional myocardial blood flow were made using the inert gas washout technique. We have previously described in detail the methods used in our laboratory (Holman et al., 1974; See et al., 1976; Cohn et al., 1977). Briefly, with the patient in the left anterior oblique position, 20 to 25 $\mathrm{mCi}$ of xenon-133 in 1 to $2 \mathrm{ml}$ saline was injected through a Judkins catheter positioned in the left main coronary artery, and then rapidly flushed with $3 \mathrm{ml}$ saline so as to enter the coronary circulation as a bolus. Washout curves were then obtained using an Anger scintillation camera as an external detector. (To minimise possible effects of fat or other nonmuscular components of myocardium on the blood flow calculation, only the slope of the curve representing the first 40 seconds of washout data were computed using a non-weighted monoexponential least squares programme.) The studies were recorded using $32 \times 32$ matrix and stored in a general purpose digital computer (PDP 11/20). The data were processed to obtain the slopes of radiotracer clearance from the entire heart and from upper and lower quadrants representing the distribution of the left anterior descending and circumflex arteries. By calculating blood flow in $\mathrm{ml} / 100 \mathrm{~g}$ per min by the Kety formula, quadrantic analysis was used to provide regional flow values. In addition, functional images were constructed (whenever technically possible) by electronically dividing the camera crystal into a $32 \times 32$ matrix and calculating blood flow in each matrix area using the initial slope method described. The highest flow rate was assigned the highest intensity level (Fig. 1). These 


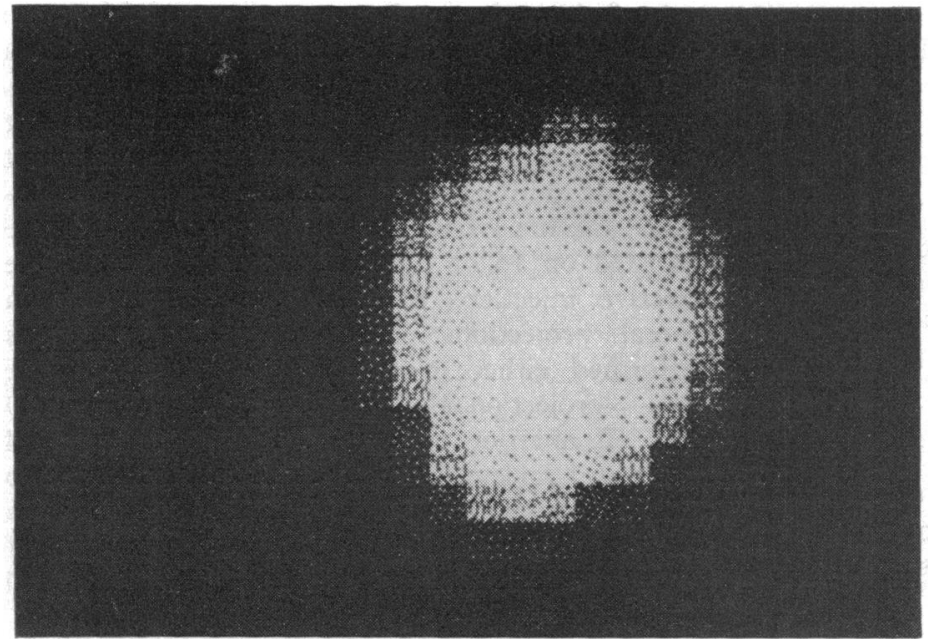

Fig. 1 Functional image from case 3 showing homogeneity of flow despite larger than expected differences between distal quadrant flow values (see Table). images provide supplemental data concerning distribution and extent of perfusion deficits.

After measurements at rest, several different interventions designed to influence blood flow were undertaken. In 6 patients, xenon-133 flow measurements were repeated 3 minutes after the administration of $0.3 \mathrm{mg}$ glyceryl trinitrate sublingually (Cohn et al., 1977). In 7 other patients, regional myocardial blood flow was measured during the hyperaemic stimulus to flow induced by the intracoronary injection of $5 \mathrm{ml}$ radiographic contrast material (Renografin-76) (Holman et al., 1976).

\section{Results}

\section{CLINICAL DATA}

The clinical data are presented in the Table. Patients were divided into three groups according to the historical characteristics of the chest pain. Seven patients in group 1 had chest pain typical of angina pectoris, as defined by a central, nonpleuritic chest pressure, provoked by exertion, emotion, or cold, lasting 2 to 10 minutes and relieved by glyceryl trinitrate. Group 2 consisted of 7 patients who also had a history compatible with typical angina, but who had pain with some atypical characteristics as well. Usually patients in this group had an exertionally related component to their chest pain, but also had such atypical characteristics as frequent unprovoked pain of unusual location or quality with episodes of several hours' or days' duration. These patients frequently complained of exertional dyspnoea as well. The third group consisted of 7 patients with entirely atypical chest pain. All these 21 patients had been difficult management problems to the referring physicians and underwent coronary angiography because in addition to their chest pain, they usually had one or more commonly accepted risk factors for coronary artery disease (see Table) and/or abnormalities on resting electrocardiograms which could be interpreted as consistent with coronary artery disease.

On physical examination, 8 patients had S4 gallops (4 in group 1, 1 in group 2, and 3 in group 3) and 2 patients in group 3 had mid to late apical systolic ejection murmurs. Chest $x$-rays and echocardiograms were unremarkable in all patients. Sixty-five per cent of all patients had changes on their resting electrocardiogram at least in part compatible with ischaemia (6 patients in group 1,3 in group 2,5 in group 3). These ranged from nonspecific ST-T wave abnormalities to $Q$ waves with deep $T$ wave inversions. Vectorcardiograms were not consistent with transmural infarction in any patient, however. One patient (case 20) had type A Wolff-Parkinson-White syndrome and another (case 18) had an isolated right bundle-branch block.

\section{EXERCISE TOLERANCE TESTS}

Twelve patients had two-step tests, 2 had bicycle ergometry, and 7 had treadmill tests. Ten tests were negative and 8 were indeterminant. Exercise tests were positive in 4 patients ( 3 in group 1 (cases 3, 4, and 5) and 1 in group 2 (case 9)). (Not included in this group was one patient in group 3 (case 20) who developed distinct ST depression $(1.0$ to $2.0 \mathrm{~mm})$ in multiple electrocardiographic leads without chest pain, but had Wolff-ParkinsonWhite syndrome in his resting electrocardiogram.) One additional patient in group 2 (case 11) devel- 
Table Clinical, haemodynamic and myocardial blood flow data in 21 patients with chest pain syndrome and normal coronary arteries

\begin{tabular}{|c|c|c|c|c|c|c|c|c|c|c|c|c|c|c|c|}
\hline \multirow[t]{3}{*}{ Case No. } & \multirow{3}{*}{$\begin{array}{l}\text { Age } \\
\text { É sex }\end{array}$} & \multirow{3}{*}{ Angina } & \multirow{3}{*}{$\begin{array}{l}\text { Response } \\
\text { to GTN }\end{array}$} & \multirow{3}{*}{$\begin{array}{l}\text { CAD risk } \\
\text { factors }\end{array}$} & \multirow[t]{3}{*}{ Exam } & \multicolumn{2}{|c|}{ Electrocardiogram } & \multirow[t]{3}{*}{$L V E D P$} & \multirow[t]{3}{*}{$E F$} & \multicolumn{6}{|l|}{$M B F$} \\
\hline & & & & & & \multirow[t]{2}{*}{ Rest } & \multirow[t]{2}{*}{ Exercise } & & & \multicolumn{3}{|l|}{ Rest } & \multicolumn{3}{|c|}{ Intervention } \\
\hline & & & & & & & & & & $W H$ & $L A D$ & $L C F$ & $W H$ & $L A D$ & $L C F$ \\
\hline $\begin{array}{l}\text { Group } 1 \\
1 \\
2 \\
3\end{array}$ & $\begin{array}{l}53 \mathrm{M} \\
42 \mathrm{M} \\
38 \mathrm{~F}\end{array}$ & $\begin{array}{l}\text { Typical } \\
\text { Typical } \\
\text { Typical }\end{array}$ & $\begin{array}{l}\text { Yes } \\
\text { Yes } \\
\text { Yes }\end{array}$ & $\begin{array}{l}\text { S } \\
\text { S,BP,O } \\
\text { S,O }\end{array}$ & $\begin{array}{l}\text { N1 } \\
\text { S4 } \\
\text { N1 }\end{array}$ & $\begin{array}{l}\text { N1 } \\
\text { NSSTTW } \\
\text { Inf TW } \downarrow \text {, } \\
\text { NSSTTW } \\
\text { V2-6 }\end{array}$ & $\begin{array}{l}\text { Neg }^{\text {M }} \\
\text { Neg }^{\mathrm{TM}} \\
\text { Pos }^{\mathrm{M}}\end{array}$ & $\begin{array}{r}6 \\
11 \\
12\end{array}$ & $\begin{array}{l}0.70 \\
0.69 \\
0.68\end{array}$ & $\begin{array}{l}51 \\
66 \\
92\end{array}$ & $\begin{array}{r}56 \\
80 \\
104\end{array}$ & $\begin{array}{l}49 \\
72 \\
83\end{array}$ & $\begin{array}{r}138 \\
48 \\
80\end{array}$ & $\begin{array}{r}153 \\
57 \\
80\end{array}$ & $\begin{array}{r}148 \mathrm{CON} \\
57 \mathrm{GTN} \\
85 \mathrm{GTN}\end{array}$ \\
\hline $\begin{array}{l}4 \\
5 \\
6 \\
7\end{array}$ & $\begin{array}{l}44 M \\
42 F \\
37 M \\
53 M\end{array}$ & $\begin{array}{l}\text { Typical } \\
\text { Typical } \\
\text { Typical } \\
\text { Typical }\end{array}$ & $\begin{array}{l}\text { Yes } \\
\text { Yes } \\
? \\
-\end{array}$ & $\begin{array}{l}\text { S,Chl,FHx } \\
\text { none } \\
\text { S,Chl,FHx } \\
\text { S,Chl,FHx }\end{array}$ & $\begin{array}{l}\text { S4 } \\
\text { S4 } \\
\text { N1 } \\
\text { S4 }\end{array}$ & $\begin{array}{l}\text { NSSTTW } \\
\text { NSSTTW } \\
\text { NSSTTW } \\
\text { Inf STTW }\end{array}$ & $\begin{array}{l}\operatorname{Pos}^{M} \\
\text { Pos }^{T M} \\
\text { Neg }^{M} \\
\text { Neg }^{M}\end{array}$ & $\begin{array}{r}11 \\
8 \\
10 \\
10\end{array}$ & $\begin{array}{l}0.63 \\
0.67 \\
0.61 \\
0.61\end{array}$ & $\begin{array}{l}76 \\
56 \\
87 \\
90\end{array}$ & $\begin{array}{r}82 \\
48 \\
103 \\
98\end{array}$ & $\begin{array}{r}83 \\
60 \\
94 \\
108\end{array}$ & $\begin{array}{l}-179 \\
149 \\
152\end{array}$ & $\begin{array}{l}\overline{201} \\
206 \\
169\end{array}$ & $\begin{array}{l}\overline{177} \mathrm{CON} \\
144 \mathrm{CON} \\
166 \mathrm{CON}\end{array}$ \\
\hline & & & & & & & & \multicolumn{2}{|c|}{ Mean \pm SEM } & $74 \pm 6$ & \multicolumn{3}{|c|}{$82 \pm 8 \quad 78 \pm 8$} & & \\
\hline $\begin{array}{l}\text { Group } 2 \\
8 \\
9 \\
10\end{array}$ & $\begin{array}{l}43 M \\
41 M \\
48 M\end{array}$ & $\begin{array}{l}\text { Intermediate } \\
\text { Intermediate } \\
\text { Intermediate }\end{array}$ & $\begin{array}{l}\text { No } \\
\text { No } \\
?\end{array}$ & $\begin{array}{l}\text { S } \\
\text { S } \\
\text { S,BP,Chl, } \\
\text { DM }\end{array}$ & $\begin{array}{l}\text { S4 } \\
\text { N1 } \\
\text { N1 }\end{array}$ & $\begin{array}{l}\text { N1 } \\
\text { NSSTTW } \\
\text { Poor R } \\
\text { wave VI-3 }\end{array}$ & $\begin{array}{l}\text { Ind } \\
\text { Pos }^{T M} \\
\text { Ind }^{T M} \\
\end{array}$ & $\begin{array}{l}12 \\
12 \\
16\end{array}$ & $\begin{array}{l}0.61 \\
0.62 \\
0.74 \\
\end{array}$ & $\begin{array}{l}98 \\
41 \\
48 \\
\end{array}$ & $\begin{array}{r}85 \\
50 \\
64 \\
\end{array}$ & $\begin{array}{r}85 \\
52 \\
56 \\
\end{array}$ & $\begin{array}{r}57 \\
36 \\
31 \\
\\
123\end{array}$ & $\begin{array}{r}51 \\
35 \\
27 \\
\\
136\end{array}$ & $\begin{array}{l}59 \text { GTN } \\
37 \text { GTN } \\
31 \text { GTN } \\
\end{array}$ \\
\hline $\begin{array}{l}11 \\
12 \\
13 \\
14\end{array}$ & $\begin{array}{l}54 \mathrm{M} \\
43 \mathrm{~F} \\
40 \mathrm{M} \\
50 \mathrm{~F}\end{array}$ & $\begin{array}{l}\text { Intermediate } \\
\text { Intermediate } \\
\text { Intermediate } \\
\text { Intermediate }\end{array}$ & $\begin{array}{l}\text { No } \\
\text { Yes } \\
\text { Yes } \\
\text { No }\end{array}$ & $\begin{array}{l}\text { S,FHx,O } \\
\text { S,O } \\
\text { S,Chl,FHx } \\
\text { FHx }\end{array}$ & $\begin{array}{l}\mathrm{Nl} \\
\mathrm{Nl} \\
\mathrm{N} 1 \\
\mathrm{Nl}\end{array}$ & $\begin{array}{l}\text { N1 } \\
\text { N1 } \\
\text { LAH } \\
\text { N1 }\end{array}$ & $\begin{array}{l}\mathrm{VT}^{\mathrm{B}} \\
\mathrm{Neg}^{\mathrm{M}} \\
\mathrm{Neg}^{\mathrm{TM}} \\
\mathrm{Neg}^{\mathrm{M}}\end{array}$ & $\begin{array}{r}12 \\
10 \\
6 \\
9\end{array}$ & $\begin{array}{l}0.82 \\
\text { pot } \\
- \\
0.74 \\
\end{array}$ & $\begin{array}{l}97 \\
70 \\
59 \\
79 \\
\end{array}$ & $\begin{array}{r}103 \\
63 \\
60 \\
90 \\
\end{array}$ & $\begin{array}{r}116 \\
69 \\
61 \\
84 \\
\end{array}$ & $\begin{array}{l}123 \\
\overline{1} \\
135\end{array}$ & $\begin{array}{l}136 \\
\overline{134} \\
\end{array}$ & $\begin{array}{l}137 \mathrm{CON} \\
- \\
\overline{136} \mathrm{CON} \\
\end{array}$ \\
\hline & & & & & & & & \multicolumn{2}{|c|}{ Mean \pm SEM } & $74 \pm 7$ & \multicolumn{3}{|c|}{$75 \pm 8 \quad 68 \pm 7$} & & \\
\hline $\begin{array}{l}\text { Group } 3 \\
15 \\
16\end{array}$ & $\begin{array}{l}41 \mathrm{M} \\
57 \mathrm{~F}\end{array}$ & $\begin{array}{l}\text { Atypical } \\
\text { Atypical }\end{array}$ & $\begin{array}{l}\text { Yes } \\
\text { No }\end{array}$ & $\begin{array}{l}\text { S,BP } \\
\text { S,Chl,FHx }\end{array}$ & $\begin{array}{l}\text { S4 } \\
\mathrm{Nl}\end{array}$ & $\begin{array}{l}\text { N1 } \\
\text { TW } \downarrow \text { I, } \\
\text { aVL, V2-6 }\end{array}$ & $\begin{array}{l}\operatorname{Ind}^{M} \\
\operatorname{Neg}^{M}\end{array}$ & $\begin{array}{l}10 \\
12\end{array}$ & $\begin{array}{l}0.79 \\
0.74\end{array}$ & $\begin{array}{l}66 \\
74\end{array}$ & $\begin{array}{l}68 \\
80\end{array}$ & $\begin{array}{l}65 \\
78\end{array}$ & $\overline{-}$ & $\overline{-}$ & $\overline{-}$ \\
\hline 17 & $42 M$ & Atypical & Yes & $\mathrm{S}, \mathrm{O}$ & $\mathrm{Nl}$ & $\begin{array}{l}\text { Poor } R \\
\text { wave V1-3 }\end{array}$ & $\mathrm{Neg}^{\mathrm{B}}$ & 4 & 0.65 & 47 & 48 & 52 & - & - & - \\
\hline $\begin{array}{l}18 \\
19\end{array}$ & $\begin{array}{l}56 M \\
49 M\end{array}$ & $\begin{array}{l}\text { Atypical } \\
\text { Atypical }\end{array}$ & $\begin{array}{l}\text { No } \\
\text { No }\end{array}$ & $\begin{array}{l}\text { S,FHx } \\
\text { S,FHx }\end{array}$ & $\begin{array}{l}\text { S4 } \\
\text { Nl }\end{array}$ & $\begin{array}{l}\text { RBBB } \\
\text { Inf } Q \\
\text { waves } \\
\text { TW } \downarrow I, a V L \\
\text { V2-6 }\end{array}$ & $\begin{array}{l}\text { Ind }^{T M} \\
\text { Ind }^{M} \\
\text {, }\end{array}$ & $\begin{array}{r}8 \\
16\end{array}$ & $\begin{array}{l}0.66 \\
0.79\end{array}$ & $\begin{array}{l}90 \\
76\end{array}$ & $\begin{array}{r}103 \\
80\end{array}$ & $\begin{array}{l}91 \\
78\end{array}$ & $\underline{83}$ & -72 & $\begin{array}{l}68 \mathrm{GTN} \\
-\end{array}$ \\
\hline 20 & $42 \mathrm{M}$ & Atypical & No & $\mathrm{DM}$ & $\begin{array}{l}\text { Apical } \\
\text { SEM }\end{array}$ & $\begin{array}{l}\text { al Type A } \\
\text { I WPW }\end{array}$ & Ind $^{M}$ & 10 & 0.68 & 128 & 128 & 148 & 172 & 218 & $196 \mathrm{CON}$ \\
\hline 21 & $51 \mathrm{~F}$ & Atypical & No & S,Chl & $\begin{array}{l}\text { Apical } \\
\text { SEM, } \\
\text { S4 }\end{array}$ & al NSSTTW & Ind $^{M}$ & 6 & 0.68 & 53 & 46 & 58 & - & - & - \\
\hline
\end{tabular}

Mean \pm SEM $\quad 79 \pm 11 \quad 80 \pm 1276 \pm 10$

Group 1 patients had typical angina by quality, location, and exertional precipitation. Group 2 patients had exertional chest pain but with additional atypical characteristics. Group 3 patients had chest pain entirely atypical of angina pectoris. CAD risk factors: S, smoking; BP, hypertension; O, obesity; Chl, hypercholesterolaemia; FHx, positive family history; DM, diabetes mellitus. Exam: SEM, systolic ejection murmur; S4, 4th heart sound; N1, normal. ECG: NSSTTW, non-specific ST + T wave changes; TW $\downarrow$, T wave inversions; Inf, standard inferior leads II, III, F; LAH, left anterior hemiblock; RBBB, right bundle-branch block; WPW, Wolff-Parkinson-White syndrome. Exercise: Ind, inderterminant; Pos, positive; Neg, negative; TM, treadmill; M, double Master's; B, bicycle. LVEDP, left ventricular end-diastolic pressure. EF, ejection fraction; pot, potentiated; WH, whole heart; LAD, left anterior descending artery; LCF, left circumflex artery. Interventions: GTN, glyceryl trinitrate; CON, contrast agent injection; MBF, myocardial blood flow.

oped a short run of ventricular tachycardia during the recovery phase, with an otherwise negative test.

\section{CATHETERISATION DATA}

In addition to normal coronary arteriograms, haemodynamic values were completely normal in 19 of the 21 patients. Two patients (one each in groups 2 and 3) had LVEDP at rest of $>15 \mathrm{mmHg}$. Left ventriculography was unremarkable in all but 3 patients. One patient in group 1 (case 4) had significant inferoapical hypokinesis, the remainder of the ventricle being quite vigorous. Two patients in group 3 also had segmental abnormalities of wall motion, one (case 16) with anterior wall asynergy and the other (case 17) with apical hypokinesis.

REGIONAL MYOCARDIAL BLOOD FLOW

Resting flows were measured for the whole heart and the two lower quadrants, which would correspond to the flow in the distribution of the distal left anterior descending and left circumflex arteries. From previous experience in our laboratory, any regional abnormalities in the distribution of blood flow would be most obvious in these quadrants 
(Holman et al., 1974; Holman et al., 1976; See et al., 1976; Cohn et al., 1977).

As indicated in the Table, blood flow measurements showed a wide range of values with whole heart blood flow ranging from 41 to $128 \mathrm{ml} / \mathrm{min}$ per $100 \mathrm{~g}$, and an average flow of $77 \mathrm{ml} / \mathrm{min}$ per $100 \mathrm{~g}$ \pm 7 (SEM). This pronounced variability in resting flow probably reflects (among other factors) the normal variability of myocardial oxygen consumption at the time of the procedure. For example, case 21 with whole heart flow of $53 \mathrm{ml} / \mathrm{min}$ per $100 \mathrm{~g}$ had a pressure-rate product of 7500 , while case 20 with whole heart flow of $128 \mathrm{ml} / \mathrm{min}$ per $100 \mathrm{~g}$ had a pressure-rate product of 13160 .

A mild degree of inhomogeneity was present in most patients, as in studies of normal control subjects (Cannon et al., 1975), with the differences between distal left anterior descending and left circumflex artery measurements (both at rest and after an intervention), ranging from 0 to 15 per cent of the higher flow value in 31 of the 34 total measurements (91\%).

When analysed according to the type of the pain, there were no significant differences in regional myocardial blood flow at rest among the three groups despite the wide range of values found in the individual patients (Fig. 2). Two patients (cases

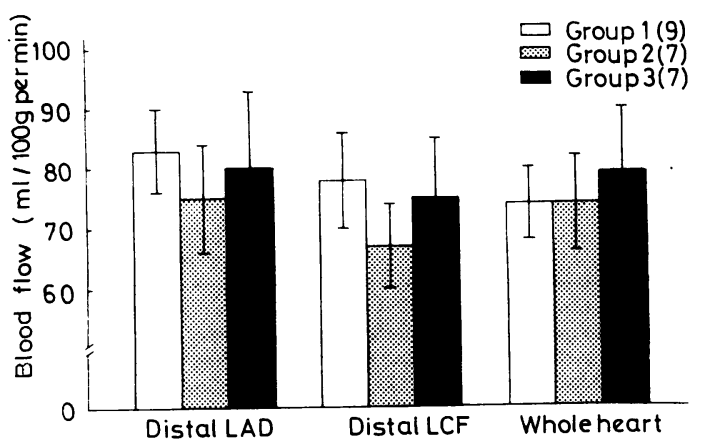

Fig. 2 Similarity of myocardial blood flow measurements (mean \pm SEM) in patients with typical angina (group 1), quasi-typical angina (group 2-see text), and typical angina (group 3). LAD, left anterior descending quadrant, $L C F$, distal left circumflex quadrant.

3 and 5) from group 1 had 20 per cent differences between the distal quadrants. Since these 2 patients also had had positive exercise tolerance tests, we further analysed the functional images (Holman et al., 1974) from the gamma camera to see if focal regions of underperfusion could be detected. In both cases, no discrete focal abnormality in per- fusion was detected on the functional image (Fig. 1), nor were focal defects noted in any of the other 10 patients in whom such images could be obtained.

The 3 patients with segmental bnormalities of wall motion (case 4, group 1 ; cases 16 and 18, group 3) had no regional flow abnormalities that corresponded to the area involved, nor were their mean flows significantly different from the rest of the study population. In the 4 patients with unequivocally positive exercise tests (cases 3,4 , and 5 in group 1, and case 9 in group 2), regional and whole heart blood flow was not significantly different from those of patients with negative tests. However, as noted before, cases 3 and 5 had $>15$ per cent difference between distal left anterior descending and left circumflex arterial blood flow and had positive tests.

To determine whether abnormalities not evident at rest could be accentuated by various stresses, xenon-133 washout was again compared after two interventions, as described earlier. For both interventions, patients in groups 2 and 3 were combined for purposes of analysis, since the numbers in each group were small. Seven patients were restudied after the intracoronary injection of radiographic contrast material. Four patients were in group 1 (cases $1,5,6$, and 7) and 3 in groups 2 and 3 combined (cases 11, 14, and 20). Both regional and whole heart blood flow increased in response to the hyperaemic stimulus in all 7 patients, and the mean flow rate achieved was not statistically different between those with classic angina and those with less typical pain patterns. The average increase in distal left anterior descending and left circumflex arterial flow was 164 per cent. Regional abnormality in coronary blood flow occurred in only one patient (case 6 , group 1 ) who had a difference of 30 per cent between the distal quadrants of the left circumflex and distal anterior descending. Case 5, who had regional inhomogeneity at rest and had had a positive exercise tolerance test, showed no regional abnormality at the higher flow rates.

In 6 patients (cases 2 and 3 in group 1 ; cases 8,9 10 , and 18 in groups 2 and 3), blood flow was remeasured after the administration of glyceryl trinitrate. Blood pressure decreased an average of 10 per cent from control values and the average decrease in distal left anterior descending and left circumflex arterial flow was 31 per cent. There was no statistical difference in the percentage decrement in blood flow between the two groups. No regional abnormalities in flow occurred, and case 3 (who had heterogeneity between lower quadrants at rest) now had less than 6 per cent difference.

Several patients in group 3 experienced almost 
constant chest pain during the catheterisation procedure, including the flow measurements. Electrocardiograms were unchanged. Flow measurements could not be obtained during pain in patients in group 1 or 2 . No patients experienced ST segment elevation consistent with Prinzmetal's angina during catheterisation or with previous episodes of pain.

\section{Discussion}

Among the large number of patients who present with chest pain syndromes and angiographically normal coronary arteries, there is a significant subgroup with typical angina pectoris and another subgroup with features that at times resemble classic angina (Bemiller et al., 1973; Kemp et al., 1973). A myriad of hypotheses (Wells et al., 1967; Eliot and Bralt, 1969; James, 1970; Herman et al., 1973; Bamrah et al., 1974; Koch et al., 1976) have been evoked to explain the source of the chest pain in these patients, including abnormal oxygen dissociation from haemoglobin, small vessel disease of the myocardium, coronary arterial spasm, primary abnormalities of myocardial metabolism, chronic hyperkinetic state, and increased coronary arterial resistance. These explanations ultimately rest upon either an abnormality of myocardial metabolism or an abnormality in the delivery of oxygen to the myocardial cells. In regard to the latter, claims of abnormal haemoglobin-oxygen dissociation in these patients have not been verified (Vokonas et al., 1974) and attention has been focused more recently on possible derangements of myocardial blood flow relative to demand.

In the present study, we have measured blood flow, both regionally and for the whole heart, in patients with normal coronary arteriograms and chest pain syndromes. The selective intracoronary injection of xenon-133, with subsequent measurements of radioisotope washout, has proved to be a clinically reliable and reproducible method of demonstrating regional heterogeneity of coronary blood flow corresponding to anatomically demonstrable lesions in patients with coronary artery disease (Holman et al., 1974; Cannon et al., 1975; Holman et al., 1976; See et al., 1976; Cohn et al., 1977). Cannon et al. (1975) have recently discussed in detail the limitations of the technique. The xenon-133 washout technique measures transmural blood flow and cannot account for the transmural heterogeneity of blood flow occurring with subendocardial ischaemia, nor can other currently used in vivo techniques. Therefore, small areas of subendocardial ischaemia cannot at present be detected by any of these methods.
Seven of our patients had chest pain identical to typical angina. Three of these patients also had positive exercise tests. The remainder of our patients fell into 2 groups: 7 with atypical chest pain, but at least in part consistent with angina pectoris (and including 1 patient with a positive exercise test and another who developed ventricular tachycardia with exercise), and 7 with completely atypical pain syndromes. More men than women were studied in our series, probably because of the greater uncertainty about the presence of obstructive coronary disease in the men. Among the 3 subgroups of patients, there were no striking differences in findings at physical examination, in noninvasive data (other than exercise testing), and in haemodynamics. While it is true that not all patients in our series had objective evidence of 'myocardial ischaemia', i.e. a positive exercise test (since we no longer routinely study lactate production), this mixture of typical and atypical symptoms, positive and negative exercise tests, etc. is what is commonly observed in this syndrome (Kemp et al., 1973).

In general, patients with this syndrome have higher flow rates than patients with angiographically documented coronary artery disease (Holman et al., 1974; Cannon et al., 1975; Holman et al., 1976; See et al., 1976; Cohn et al., 1977). Within our present study group, we could not find significant differences in flow rates between the patients with less typical anginal patterns compared with those with more typical angina patterns. While 2 group 1 patients at rest (both with positive exercise tests) and 1 group 1 patient with contrast induced hyperaemia had regional inhomogeneities of blood flow by quadrantic analyses, no localised perfusion defects were observed on the functional images of myocardial perfusion. The latter technique is a sensitive measure of the presence and extent of focal alterations in perfusion, since the resultant image is based on separate washout measurements from small regions $(0.5 \times 0.5 \mathrm{~cm})$ of the camera crystal (Holman et al., 1974). The heterogeneity observed with quadrant analyses in 3 of 34 total measurements may have resulted from excess background (lung activity) in one of the quadrants. In 2 of these 3 patients, functional images could be obtained and showed homogeneous perfusion, as did 10 other patients without significant interquadrant differences in blood flow.

We were unable to obtain flow measurements during episodes of chest pain in group 1 and 2 patients, and Schmidt et al. (1976), using a similar xenon-133 technique to measure blood flow response to atrial pacing in 6 patients with the same syndrome, was also unable to obtain blood flow measurements during pain. However, Raphael 
et al. (1976), using a noninvasive thallium-201 technique that can be combined with exercise testing obtained myocardial scintigrams in 9 patients with this syndrome during treadmill stress tests. Despite the presence of both chest pain and an abnormal exercise test in all 9 patients, no myocardial perfusion abnormalities were observed in any patient. By contrast, Korhola et al. (1977), using a semi-selective method of injecting xenon-133, reported that 50 per cent of their patients with normal coronary angiograms, positive exercise tolerance tests, and chest pain had perfusion abnormalities on resting myocardial scintigrams, with associated reduced flow rates in the region involved. They recorded very high flow rates at rest so that the 'underperfused' regions actually had flows in the normal range. This difference in flow rates, the difference in technique, and the somewhat different patient population $(30 \%$ had documented myocardial infarctions, which are rare with the syndrome of angina and normal coronary arteriograms (Kemp et al., 1973)) may help explain the discordance in findings in this study compared with ours and that of Raphael et al. (1976).

Because of the greater augmentation of myocardial blood flow obtained with contrast agentinduced hyperaemia compared with atrial pacing, we have found this to be a more useful intervention for differentiating between our patients with and without coronary artery disease (Holman et al., 1976). In the present study, the augmentation of myocardial blood flow was not significantly different in patients with and without classic angina. After sublingual administration of glyceryl trinitrate (with its resulting fall in blood pressure and myocardial oxygen requirements) we have usually noted less of a decrease in regional myocardial blood flow (and even an occasional increase) in patients with coronary artery disease compared with those with normal coronary arteriograms (Cohn et al., 1977). In the present study, the decline in myocardial blood flow was not significantly different in patients with and without typical angina. Patients with localised abnormalities of left ventricular wall motion did not have the reduction in flow seen in patients with coronary artery disease with similar findings (See et al., 1976), suggesting that these abnormalities were probably not related to fibrosis.

Thus, in evaluating distal quadrant flow patterns as well as functional images made up of even smaller regions, we could not show significant abnormalities of myocardial blood flow using the xenon-133 washout technique either at rest or during interventions that alter flow in most patients with normal coronary arteriograms and chest pain syndromes. Usually homogeneous flow patterns at rest, definite decrement in flow with glyceryl trinitrate, and pronounced augmentation of flow with intracoronary contrast agent stimulation would make such fixed derangements of myocardial perfusion as small vessel disease unlikely in this syndrome. Three alternative explanations remain : first, since measurements could not be obtained during pain, transient alterations in coronary vascular tone cannot be ruled out; second, alterations in myocardial metabolism may be present; third, one cannot dismiss the strong possibility that most of the patients have non-cardiac pain and that the clinical abnormalities found in many of them are either fortuitous or can be found randomly in the normal population whether or not they are influenced by cardiac or non-cardiac phenomena.

\section{References}

Arbogast, R., and Bourassa, M. G. (1972). Myocardial function during atrial pacing in patients with angina pectoris and normal coronary arteriograms. American fournal of Cardiology, 32, 257-263.

Bamrah, V. S., Bahler, R. C., and Rakita, L. (1974). Hemodynamic response to supine exercise in patients with chest pain and normal coronary arteriograms. American Heart fournal, 87, 147-157.

Bemiller, C. R., Pepine, C. J., and Rogers, A. K. (1973). Long-term observations in patients with angina and normal coronary arteriograms. Circulation, 47, 36-43.

Boudoulas, H., Cobb, T. C., Leighton, R. F., and Wilt, S. M. (1974). Myocardial lactate production in patients with angina-like chest pain and angiographically normal coronary arteries and left ventricle. American fournal of Cardiology, 34, 501-505.

Bruce, R. A., and Hornstein, T. R. (1969). Exercise stress testing in evaluation of patients with ischemic heart disease. Progress in Cardiovascular Diseases, 11, 371-390.

Cannon, P. J., Sciacca, R. R., Fowler, D. L., Weiss, M. B., Schmidt, D. H., and Casarella, W. J. (1975). Measurement of regional myocardial blood flow in man: description and critique of the method using xenon-133 and a scintillation camera. American fournal of Cardiology, 36, 783-792.

Cohn, P. F., Maddox, D. E., Holman, B. L., Markis, J. E., Adams, D. F., and See J. R. (1977). Effect of sublingually administered nitroglycerin on regional myocardial blood flow in patients with coronary artery disease. American fournal of Cardiology, 39, 672-678.

Cohn, P. F., Vokonas, P. S., Most, A. S., Herman, M. V., and Gorlin, R. (1972). Diagnostic accuracy of two-step post-exercise ECG: results in 305 patients studied by coronary arteriography. Fournal of the American Medical Association, 220, 501-506.

Dwyer, E. M., Dell, R. B., and Cannon, P. J. (1972). Regional myocardial blood flow in patients with angina and normal coronary arteries (abstract). Circulation, 45 and 46 , Suppl. II, 6.

Dwyer, E. M., Jr., Wiener, L., and Cox, J. W. (1969). Angina pectoris in patients with normal and abnormal coronary arteriograms. American fournal of Cardiology, 23, 639-646.

Eliot, R. S., and Bralt, G. (1969). The paradox of myocardial ischemia and necrosis in young women with normal coronary arteriograms. American fournal of Cardiology 23, 633-638. 
Herman, M. V., Cohn, P. F., and Gorlin, R. (1973). Anginalike chest pain without identifiable cause. Annals of Internal Medicine, 79, 445-447.

Holman, B. L., Adams, D. F., Jewitt, D., Eldh, P., Idoine, J., Cohn, P. F., Gorlin, R., and Adelstein, S. J. (1974). Measuring regional blood flow with $133 \mathrm{xe}$ and the Anger camera. Radiology, 112, 99-107.

Holman, B. L., Cohn, P. F., and Adams, D. F., See, J. R., Roberts, B. H., Idoine J., and Gorlin, R. (1976). Regional myocardial blood flow during hyperemia induced by contrast agent in patients with coronary artery disease. American fournal of Cardiology, 38, 416-421.

James, T. N. (1970). Angina without coronary disease (sic). Circulation, 42, 189-191.

Kemp H. G., Jr., Vokonas, P. S., Cohn, P. F., and Gorlin, R. (1973). The anginal syndrome associated with normal coronary arteriograms. American fournal of Medicine, 54, 735-742.

Koch, F. H., Billingham, M. E., Rider, A. K., Mason, J. W., Cipriano, P. R., and Hancock, E. W. (1976). Pathophysiology of 'angina' with normal coronary angiograms (abstract). Circulation, 53 and 54, Suppl. II, 173.

Korhola, O., Valle, M., Frick, M. H., Wiljasalo, M., and Riihimäki, E. (1977). Regional myocardial perfusion abnormalities on xenon-133 imaging in patients with angina pectoris and normal coronary arteries. American fournal of Cardiology, 39, 355-359.

Mammohansingh, P., and Parker, J. O. (1975). Angina pectoris with normal coronary arteriograms: hemodynamic and metabolic response to atrial pacing. American Heart fournal, 90, 555-561.

Raphael, L. D., Cowley, M. J., Logic, J. R., Gillis, R., and Coghlan, H. C. (1976). ${ }^{201}$ Thallium exercise myocardial scintigraphy in patients with 'angina and normal coronary arteriograms' (abstract). Circulation, 53 and 54, Suppl. II, 217.

Sample, K., Covvey, H. D., Wigle, E. D., and Adelman, A. G. (1974). The clinical spectrum and hemodynamics of women with chest pain and normal coronary arteries (abstract). American fournal of Cardiology, 33, 168.

Schmidt, D. H., Weiss, M. B., Casarella, W. J., Fowler, D. L., Sciacca, R. R., and Cannon, P. J. (1976). Regional myocardial perfusion during atrial pacing in patients with coronary artery disease. Circulation, 53, 807-819.

See, J. R., Cohn, P. F., Holman, B. L., Roberts, B. H., and Adams, D. F. (1976). Angiographic abnormalities associated with alterations in regional myocardial blood flow in coronary artery disease. British Heart fournal, 38, 1278-1285.

Vokonas, P. S., Cohn, P. F., Klein, M. D., Laver, M. B., and Gorlin, R. (1974). Hemoglobin affinity for oxygen in the anginal syndrome with normal coronary arteriograms. fournal of Clinical Investigation, 54, 409-415.

Wells, R., Heinle, R. A., Kemp, H. G., and Gorlin, R. (1967). Abnormalities of the microcirculation in patients with anginal syndrome with normal coronary arteries studied by cineangiography (abstract). Circulation, 35 and 36, Suppl. II, 268.

Zoll, P. H., Wessler, S., and Blumgart, H. L. (1951). Angina pectoris: a clinical and pathologic correlation. American of Medicine, 11, 331-357.

Requests for reprints to Dr Peter F. Cohn, Cardiovascular Division, Peter Bent Brigham Hospital, 721 Huntington Avenue, Boston, Massachusetts 02115, U.S.A. 